\title{
Evaluation of Groundwater Resources in Aiyar Basin: A GIS Approach for Agricultural Planning and Development
}

\author{
K. Balasubramani ${ }^{1}$, M. Gomathi ${ }^{2}$, K. Kumaraswamy ${ }^{2 *}$ \\ ${ }^{1}$ School of Earth Sciences, Central University of Tamil Nadu, CUTN Bridge Neelakudy, Tamil Nadu, 610005, India \\ ${ }^{2}$ Department of Geography, Bharathidasan University, Palkalaiperur, Tiruchirappalli, Tamil Nadu, 620024, India \\ *Corresponding Author: kkumargeo@ gmail.com
}

Received 19 December 2019/ Revised 26 December 2019/ Accepted 28 December 2019/ Published 30 December 2019

\begin{abstract}
Groundwater is an integral part of agriculture and rural development. In the present study, an attempt has been made to analyse the spatio-temporal variations of groundwater level in Aiyar basin using spatial statistics and GIS to associate the variations with cropping pattern; to suggest agricultural planning and development practices. The groundwater level was measured in the basin through 40 dug wells in July (premonsoon) and January (post-monsoon) besides water level data collected from 50 permanent monitoring wells for thirty-six years (1980-2015) from the State Groundwater Division for spatial and statistical analyses. In order to understand the fluctuations in the groundwater level of the basin, seasonal groundwater levels were computed for pre and post-monsoon seasons. To understand the regional variations in water level fluctuations, hot spot analysis is carried out using Getis-Ord Gi* statistics in GIS. Based on z-score, the basin is divided into five clusters. The long-term fluctuation of groundwater level in each cluster was examined independently and the trends were determined. Based on the trend of groundwater level and cropping pattern of the clusters, suggestions are drawn for each cluster for agricultural planning and development. By comparing the clusters, it is found that the foot of Kollimalai and Pachamalai hills (cluster4 and 5) experiences a severe drop in groundwater level. During the last 36 years, the water table of these clusters is decreased from $4 \mathrm{~m}$ to $10 \mathrm{~m} \mathrm{BGL}$ and the rate of decline is very severe after the drought years of 2002-2003. The main reason for the declining water level in this region is the cultivation of wet crops especially paddy and sugarcane in extensive areas, although irrigation facilities are limited and the climate is conducive only for rainfed agriculture. Hence, it is necessitated to reduce the acreage of wet crops and compensate by suitable dry crops in these clusters.
\end{abstract}

Keywords: Groundwater, Agriculture, GIS, Hot Spot Analysis, River basin, SDG

\section{Introduction}

Groundwater resources have provided an invaluable source of irrigation to the crops but widespread and largely unregulated groundwater withdrawals by agriculture have resulted in depletion and degradation of some of the world's most accessible and high-quality aquifers (FAO, 2011). Currently, agriculture uses 11 per cent of the world's land surface for crop production but accounts for 70 per cent of all water withdrawn from aquifers, streams and lakes (FAO, 2016). The rapid rate of growth in irrigation is perhaps best illustrated in India, where the amount of land irrigated by surface water has doubled between 1950 and 2000, but the area irrigated from aquifers has increased by 113 times during the same period (Morris et al., 2003). An increasing practice of irrigated agriculture using groundwater resources in India has already created a problem of salinization (Singh, 2018). Now, the groundwater shortage and groundwater quality deterioration 
are the most common problems in irrigated agricultural areas (Nachtergaele et al., 2011). The condition of groundwater resources is becoming more and more critical in the arid and semi-arid lands of the country (Gupta and Sharma, 2018). Although agricultural production of semi-arid lands is increased steadily, groundwater extraction for irrigated agriculture in semi-arid lands has had negative effects on natural resources which become a serious threat to the food security of the country (Bindraban et al., 2012). In order to satisfy human needs as well as sustaining natural resources and ecosystems, it is necessary to regulate farming systems and introduce conservation schemes preferably at a basin scale through a systematic hydrological assessment.

Monitoring of the groundwater level of observation wells is the principal source of information on the effects of hydrologic stresses on groundwater systems (Ahmadi and Sedghamiz, 2007). Further, understanding the spatial pattern of groundwater level and its long-term trends are essential for making any management decision for agricultural development (Reghunath et al., 2005). In recent years, several studies have reported that there are large variations in groundwater levels over many parts of India, suggesting a detailed study needs to be undertaken to elucidate the behaviour of groundwater level fluctuations in both, spatial and temporal scales for proper agricultural planning and development (Anbazhagan and Ramasamy, 2005; Kumar et al., 2007; Sivasankar et al., 2013; Buvaneshwari et al., 2017). With this background, the present study attempts to assess the spatio-temporal dynamics of groundwater level in Aiyar basin through GIS and geostatistical modelling towards suggesting strategies for sustainable agriculture development.

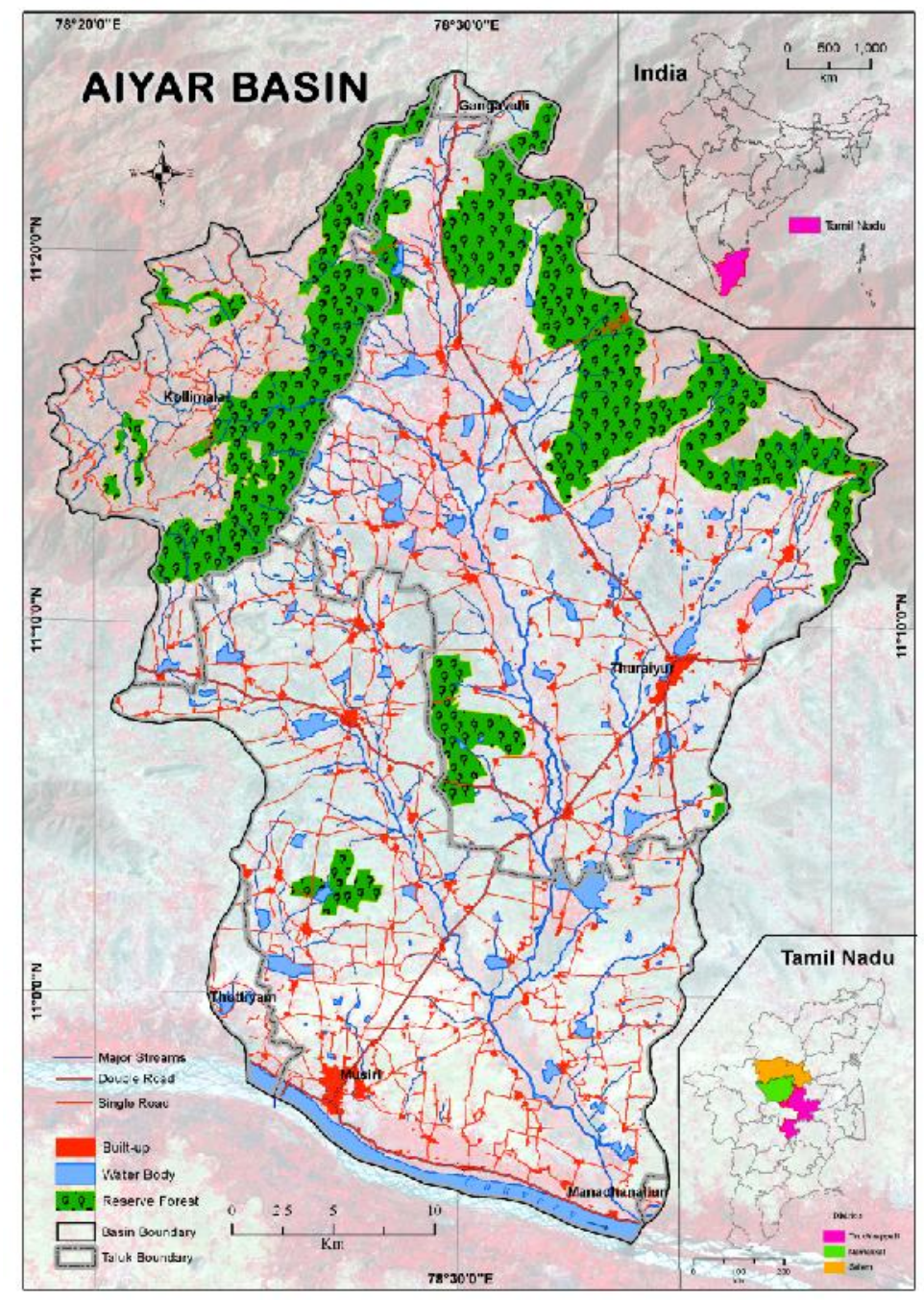

Figure 1. Base map of the study area along with its location in India 
The river Aiyar is the major sub-basin of the middle part of the Cauvery basin, Tamil Nadu (Figure 1). The total area of the basin is 1,360 sq.km, of which about 25 per cent of the basin is covered by hilly terrain (Pachamalai in the Northeast and Kollimalai in the Northwest). The basin is mainly drained by seasonal tributaries of the river Cauvery. The physical and socio-economic characteristics indicate that Aiyar basin is dominated by agricultural activities and abode for four lakh rural population. The average annual rainfall for the basin is $758 \mathrm{~mm}$ that is gradual decreases from northern uplands to southern plains, following the general slope of the basin. The basin receives about 82 per cent of its rainfall during southwest and northeast monsoon seasons (October - December) with a long dry season during remaining months. Even though the basin is climatologically disadvantaged, about 70 per cent of the basin area is utilised for agricultural purposes with the help of groundwater resources. However, over a past three decades it is noticed that the average proportion of agricultural labours to the total population is in the decreasing phase (Gomathi and Kumaraswamy, 2016). Therefore, it is pertinent to assess the potentials and dynamics of groundwater resources for suggesting suitable agricultural development measures in the basin.

\section{Methods}

In this study, seasonal groundwater levels (pre-monsoon and post-monsoon) were measured in 40 open wells across the study area during 2014-16. In order to understand the long-term fluctuations in groundwater levels, data of 36 years (1980-2015) recorded at 50 observation wells were collected from the State Ground and Surface Water Resources and Development Centre, Chennai. The spatial pattern of groundwater level was analysed for the two seasons such as pre-monsoon (July) and post-monsoon (January) during 2014-16. The difference of water levels between pre-monsoon and post-monsoon was computed to infer the fluctuations in groundwater level and associated impacts on cropping pattern. To estimate the longterm trend of groundwater level, the average values of water level was calculated for each year. Kriging interpolation technique was used to estimate the values for unknown locations. To understand the spatial variations in long-term fluctuations of groundwater level, Getis-Ord Gi* statistic (hot-spot analysis) was computed for 90 observation wells to identify the different clusters of groundwater levels. The Hot Spot Analysis tool in ArcGIS was used to calculate the statistic. This statistic identifies the clustering of high and low values based on z-score and p-value (Mitchell, 2005). Both z-scores and p-values are associated with the standard normal distribution of the water level data where the p-value is a probability that the observed spatial pattern was created by some random process and z-scores are simply standard deviations. Statistically, the larger the positive z-score represents more clustering of high values (hot spot) where the depth to water level is deep and surrounded by well locations with deeper water levels. Similarly, the negative z-score represents the clustering of shallow water levels (cold spot). The long-term fluctuation in the water level of each cluster was examined independently based on groundwater level data of respective wells for 36 years (1980-2015). The plateau region of Kolli hills is identified with cold spot (shallow water level) but due to lack of long-term water level data (no monitoring wells established by groundwater division), the area was excluded from the present analysis.

The agricultural data (G-Return) pertaining to 130 revenue villages of the basin were also collected from District Statistical offices for the period between 2010-11 and 2015-16. The location quotient method of Bhatia (1965) and crop diversification method of Gibbs and Martin (1962) were used respectively to determine crop concentration and crop diversification of the basin. Geographic Information System (GIS) was used to analyse and integrate the results of cropping pattern with groundwater resources and to prepare thematic maps. 


\section{Results and Discussion}

\subsection{Spatial Pattern of Groundwater Level}

The groundwater level is an important variable as it indicates indirectly the groundwater potential zones, especially in the semi-arid regions (Balasubramani, 2018). The groundwater level mainly depends upon rainfall, subsurface lithology and weathering. During the pre-monsoon season (July), the depth to groundwater level in the basin is found to vary from 1.8 to $29.1 \mathrm{~m}$ from the ground surface. Due to the natural recharge of groundwater during the rainfall period (September - December), the water level increases throughout the basin and varies from 1.3 to $25.8 \mathrm{~m}$ during the post-monsoon season (January). The groundwater levels in the study area are classified into five categories viz., $<8 \mathrm{~m}$ (shallow), $8-12 \mathrm{~m}$ (shallow-moderate), $12-16 \mathrm{~m}$ (moderate), $16-20 \mathrm{~m}$ (deep) and $>20 \mathrm{~m}$ (very deep). The results reveal that 30 per cent of the wells fall under very deep groundwater level category and 17 per cent of the wells fall under shallow category during the pre-monsoon period. During post-monsoon season, the condition of very deep and shallow water levels is almost reverse where 29 per cent of the wells fall under shallow and 16 per cent of the wells are observed with very deep groundwater levels. The rise of water table level in January might be the direct effect of aquifer recharge in the preceding months, especially the northeast monsoon season.
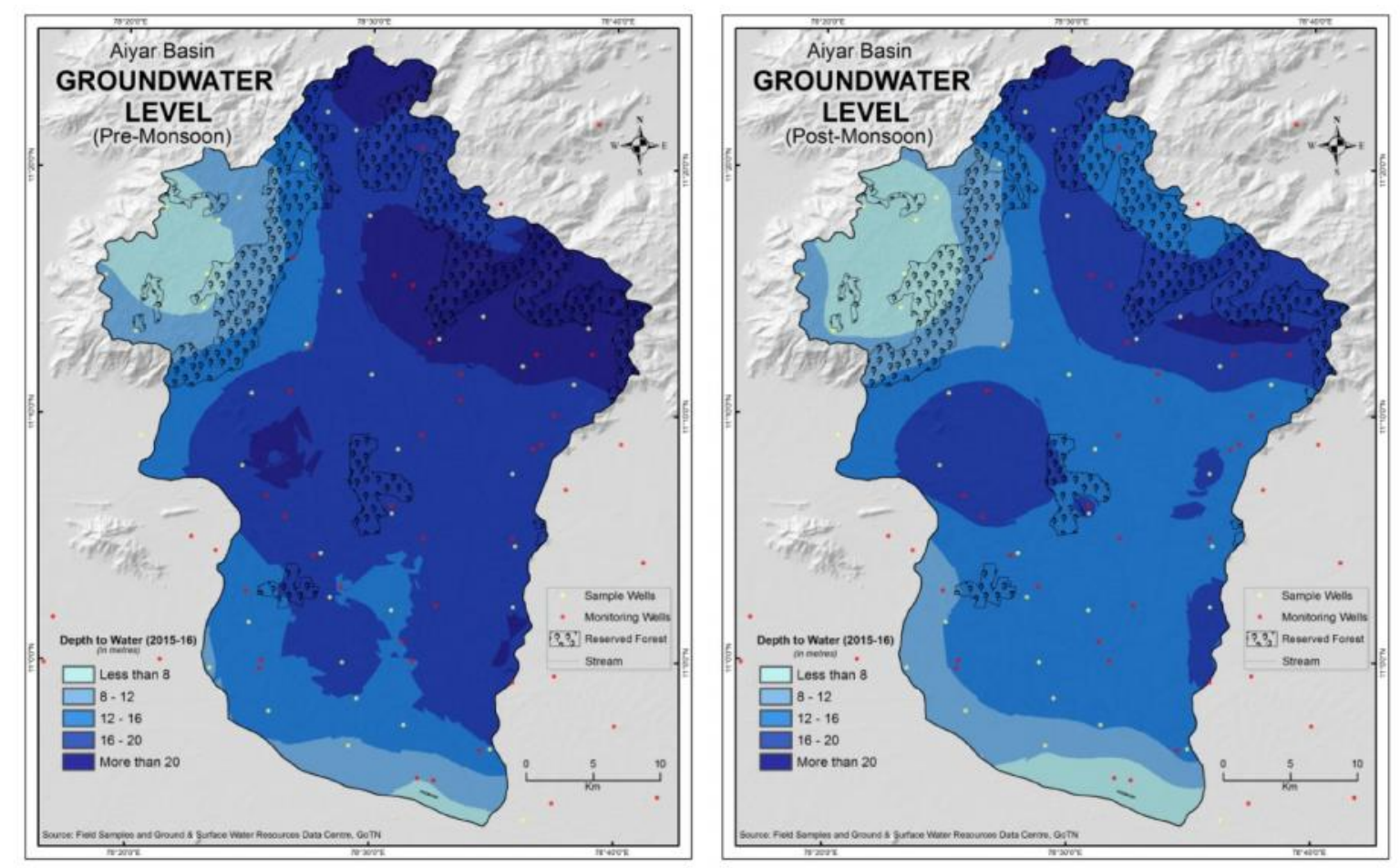

Figure 2. Depth to Groundwater Level during Pre and Post Monsoon Seasons

The interpolated groundwater level surface shows the spatial pattern of groundwater level for pre and post monsoon seasons (Figure 2). It is inferred that the groundwater flow direction of the study area is from north to south. The water level is deeper in relatively elevated areas especially along the foot of Pachamalai hills (northeastern parts) and shallower in southern plain surfaces. The plateau region of Kollimalai hills is marked with isolated shallow groundwater levels. While comparing the groundwater level of post-monsoon with pre-monsoon, north-eastern parts of the study area are experiencing increased groundwater level drop 
and it shows that more attention should be paid to cropping pattern of these areas to prevent further degradation of groundwater potential.

The seasonal water level fluctuation varies from 0 to $9.3 \mathrm{~m}$. More than one-third of the wells have reported a higher level of groundwater fluctuation $(>3 \mathrm{~m})$. The north-eastern part of the basin is more vulnerable to groundwater fluctuation as about 60 per cent of the wells located in this region express groundwater fluctuation of more than $4 \mathrm{~m}$. Since a very deep water table as well as higher fluctuation is observed in the north-eastern foothills, this area requires better groundwater management practices for sustainable agricultural production.

\subsection{Temporal Pattern of Groundwater Level}

The rise and fall of groundwater level directly depend on the rainfall pattern of a year, whether it is above or below the normal. A continued increase of extraction without adequate recharge in the aquifers will lead to the downward pull of the groundwater level over years (Balasubramani et al., 2019). In order to understand the long-term fluctuations, monthly water level data of 50 monitoring wells for the period were used. The hydrograph of the basin prepared using data of monitoring wells of the basin between 1980 and 2015 shows that there is a cyclic trend of groundwater level depending upon the rainfall pattern of the basin (Figure 3). However, the gap between trends in rainfall and groundwater level is widening in recent years. In 2000 , the average depth to groundwater level of the basin is $5.5 \mathrm{~m}$ and it has declined to $13 \mathrm{~m}$ in 2015 with a rate of $0.5 \mathrm{~m}$ of lowering of water table per year (Figure 4). The main reason inferred for such a declining level of groundwater in this region is the overexploitation of groundwater mainly for irrigation purposes.

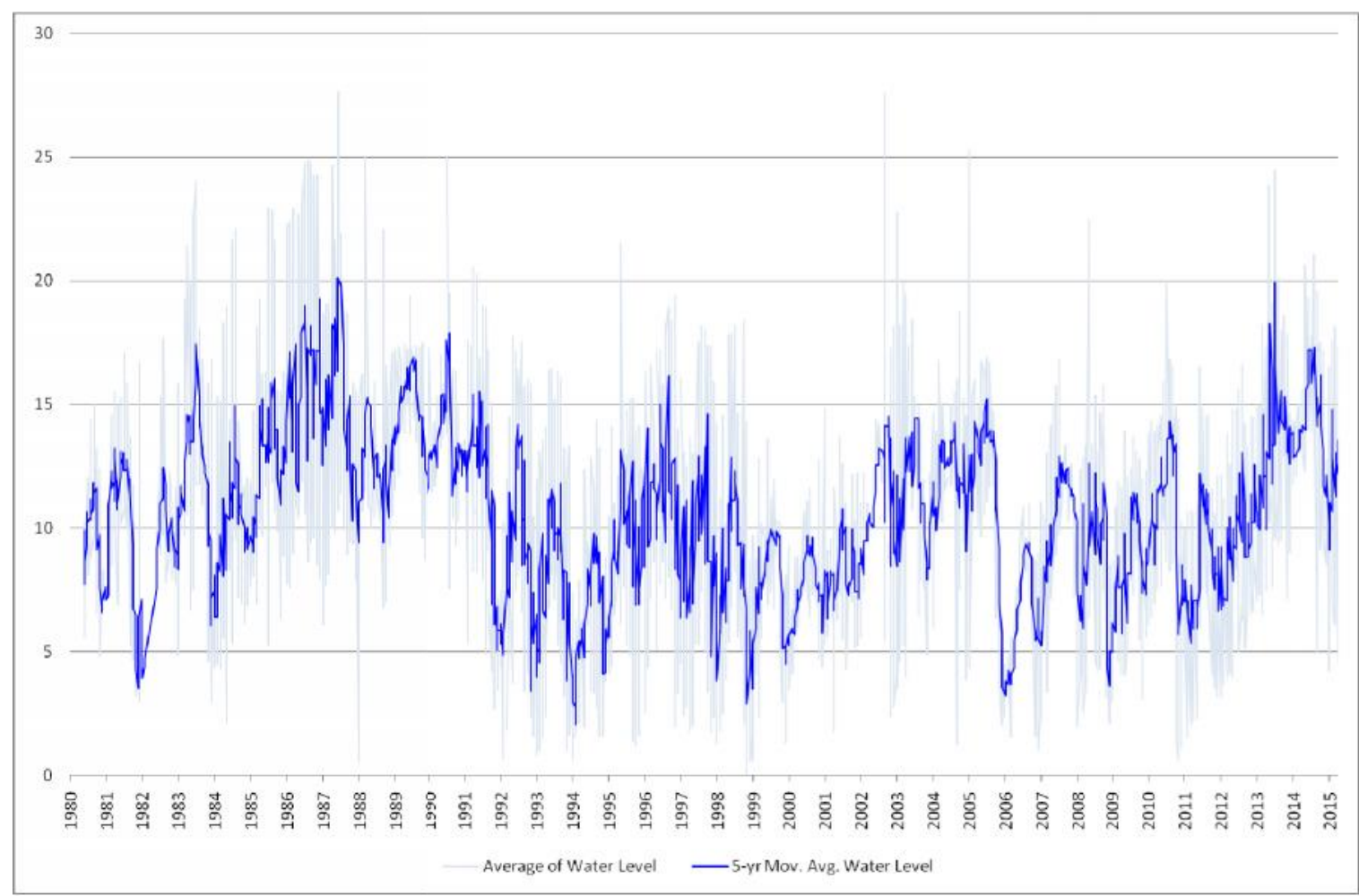

Figure 3. Hydrographs Based on Average Water Levels of Monitoring Wells of the Study Area (1980-2015) 


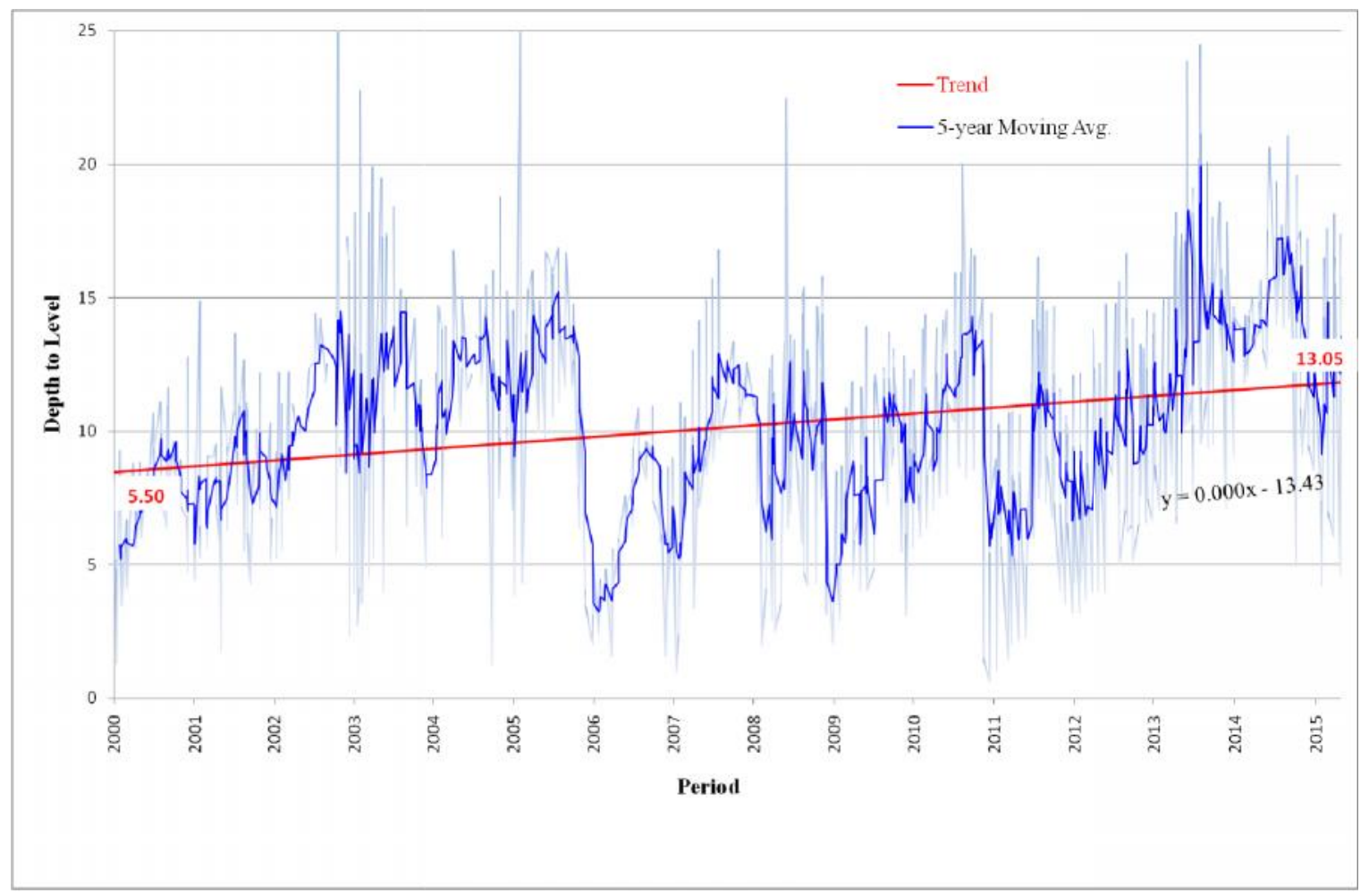

Figure 4. Trend of Average Water Levels (2000-2015)

\subsection{Regional Variations in Trends}

Based on z-score of the hotspot analysis, the study area is divided into five clusters namely cluster-1 $(<-2.0)$, cluster-2 (-2.0 to -1.0$)$, cluster-3 (-1.0 to 1.0$)$, cluster-4 (1.0 to 2.0$)$ and cluster-5 (> 2.0). The cluster-1 is formed in the southern flood plains where the water level is shallow and cluster- 2 is formed parallel to cluster-1 on the northern side (Figure 5). The clusters-4 and-5 are formed in the foot of Kollimalai and Pachamalai hills respectively where groundwater levels are deeper. The central portion of the study area is identified with cluster-3.

The long-term fluctuation and trend in water level for each cluster was computed and shows that the average depth to the water level in cluster-1 is $6.7 \mathrm{~m}$ and the standard deviation is $1.2 \mathrm{~m}$. Since the observation wells of this region show a limited fluctuation of water level over 36 years, there is no significant change in water level. It is understood that the aquifer system of cluster-1 has relatively similar characteristics throughout the plain and has good groundwater recharge potential for wet crop cultivation practices. The average depth to the water level in cluster- 2 is $9.7 \mathrm{~m}$ which is higher than cluster- 1 and the standard deviation is $3 \mathrm{~m}$. The cluster-2 has experienced a cyclic trend of water level where the period 19801991 experienced a drop in water level below the average and the period 1991-2003 observed with the rise of water level above the average. After 2003, the water level in the region is highly fluctuating and it closely depends on the rainfall pattern of the region. In general, the cluster-2 is suitable for wet crops during wet monsoon years.

Since the cluster-3 is dominantly covered by pediments, the average depth to the water level of this region is reported as $14 \mathrm{~m}$ with a standard deviation of $2.9 \mathrm{~m}$. Similar to cluster-2, this region is also experienced a cyclic trend of water level, but the overall trend shows a decline in water level from $13 \mathrm{~m}$ to $15 \mathrm{~m}$. Hence, the present cropping pattern should be monitored and regulated. 


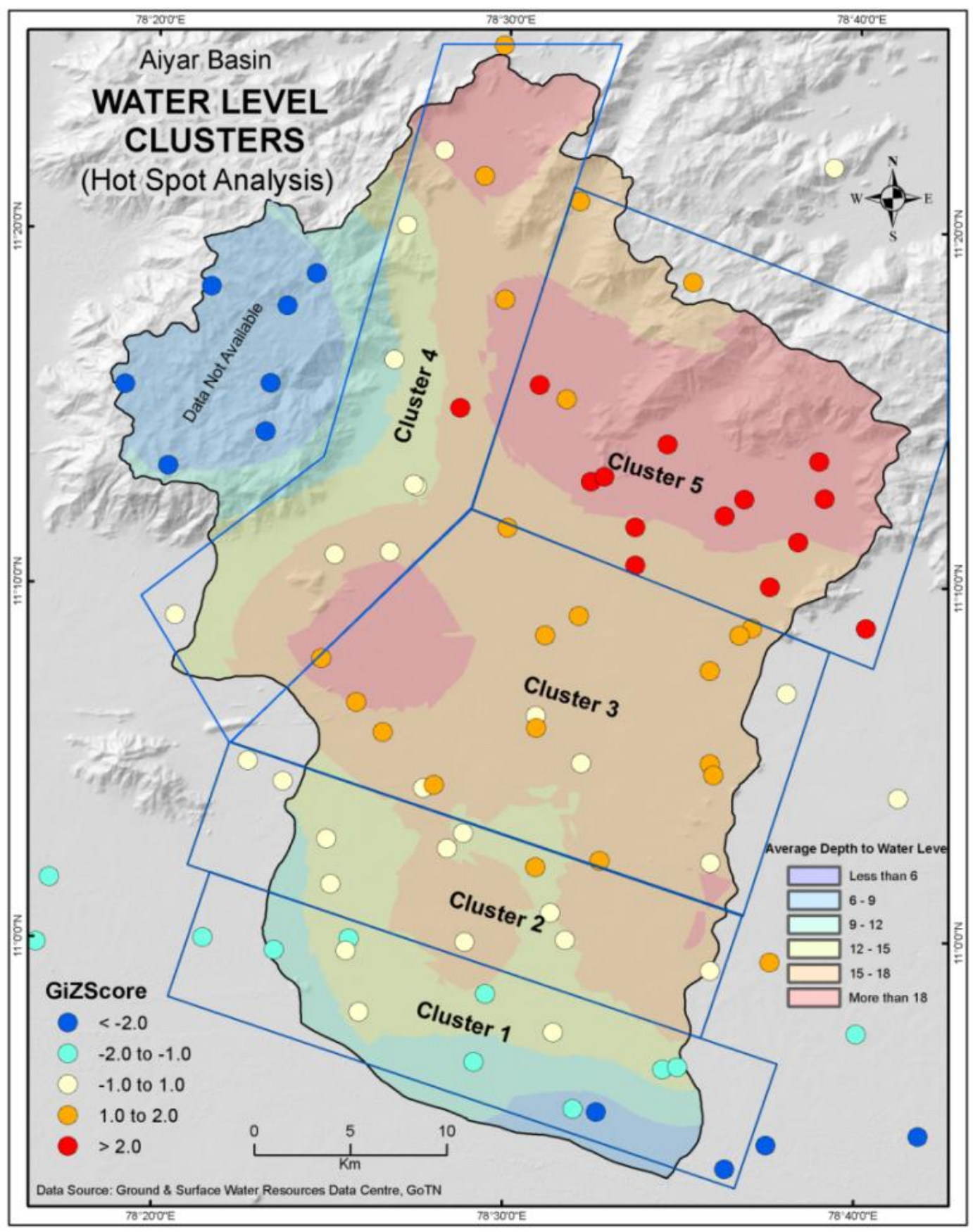

Figure 5. Clusters of Groundwater Wells

It is found that the foot of Kollimalai hills (cluster-4) experiences a severe drop in groundwater level with a rate of $0.2 \mathrm{~m}$ per year. During the last 36 years, the water table of this cluster is decreased from $4 \mathrm{~m}$ to $10 \mathrm{~m}$ and the rate of decline is severe after the drought years of 2002-2003. Because the average water level between 1980 and 2001 was $5.4 \mathrm{~m}$ and it has been doubled during the last 15 years $(10.4 \mathrm{~m})$. The deviation of water level from the long-term average is also higher in this cluster $(3.4 \mathrm{~m})$. The main reason for the declining water level in this region is the cultivation of wet crops especially paddy and sugarcane in extensive areas.

The water level in the north-eastern parts of the basin (foothills of Pachamalai) is deeper and statistically termed as a hot spot. The average water level of this region is $10.5 \mathrm{~m}$ with a standard deviation of $2.9 \mathrm{~m}$. Even though the long-term data of water level signifies a positive trend, the area was frequently 
identified with a cone of depression in the water table. The periods 1988-90, 1995-97, 2003-05 and 2013-15 are marked with a cone of depression patterns due to failure of rainfall during 1988-90, 1995, 2002 and 2011-13. This indicates that the supply of water (recharge) is slow and but extraction of groundwater is rapid and alarming. The geochemical analysis of water samples shows that the classes of poor groundwater i.e. very high salinity hazard and moderate sodium hazard are also mainly found in the cluster-5.

\subsection{Cropping Pattern of the Basin}

Paddy and sorghum are first ranking crops over extensive parts of the basin comprising about 75 per cent of the villages. The recent distributional pattern of the dominance of these two crops reflects differences in the availability of groundwater resources. The high concentration of maize and cotton occurs mainly in the north-eastern parts of the basin and proves that the groundwater resource of this region is depleted in recent years. The diversification index value of the basin is 0.88 represents a very high crop diversification as a whole. The areas of very high crop diversification found in the foothills region, especially in north-eastern foothills, indicate that the groundwater exploitation in cluster-5 is abnormal.

\section{Conclusion}

Groundwater is the basis for almost all kinds of human activities in the basin. The spatial pattern of groundwater level shows that the foot of Pachamalai (north-eastern part) has very deep water table with marked seasonal fluctuations and cone of depressions. The temporal pattern of groundwater level signifies that the foot of Kolli hills (north-western part) has a significant decline of groundwater level in the last two decades. At the same time, the cropping pattern of these regions is still water-intensive and highly depends on open and bore wells. Therefore, conversion of wet cropping system to dry crops and implementation of water harvesting systems such as recharge wells, percolation ponds and check dams in northern parts are strongly suggested for sustainable development of agriculture in the basin.

\section{Conflict of Interest}

The authors declare that there is no conflict of interest with any financial organization regarding the material discussed in the article.

\section{References}

Ahmadi, S. H., Sedghamiz, A., (2000). Geostatistical Analysis of Spatial and Temporal Variations of Groundwater Level. Environment Monitoring and Assessment, 129:277-294. http://dx.doi.org/10.1007/s10661-006-9361-z

Anbazhagan, S., Ramasamy, S.M., (2005). Evaluation of areas for artificial groundwater recharge in Ayyar basin, Tamil Nadu, India through statistical terrain analysis. Journal Geological Society of India, 67(1):59-68.

Balasubramani, K., (2018). Physical resources assessment in a semi-arid watershed: An integrated methodology for sustainable land use planning. ISPRS Journal of Photogrammetry and Remote Sensing 142:358-379. https://doi.org/10.1016/j.isprsjprs.2018.03.008

Balasubramani, K., Rutharvel Murthy, K., Gomathi, M., Kumaraswamy, K., (2019). Integrated assessment of groundwater resources in a semi-arid watershed of South India: implications for irrigated agriculture. GeoJournal, 1-23 https://doi.org/10.1007/s10708-019-10050-0 
Bindraban, P.S. Marijnvan der V., LimingYe, et al., (2012). Assessing the impact of soil degradation on food production. Current Opinion in Environmental Sustainability, 4(5): 478-488 https://doi.org/10.1016/j.cosust.2012.09.015

Buvaneshwari, S. Riotte, J., Ruiz, L. et al., (2017). Impacts of land-use and soil properties on groundwater quality in the hard rock aquifer of an irrigated catchment: the Berambadi (Southern India). In proceedings of 19th EGU General Assembly, Vienna.

FAO, (2011). The state of the world's land and water resources for food and agriculture - Managing systems at risk. Food and Agricultural Organization, Rome. http://www.fao.org/docrep/017/i1688e/i1688e.pdf (15 November 2019)

FAO, (2016). Land degradation assessment in drylands - Manual for local level assessment of land degradation and sustainable land management Part-1. Food and Agricultural Organization, Rome http://www.fao.org/ publications/card/en/c/40875549-ecc8-4388-b944-26edc9b58272 (15 November 2019)

Gomathi, M. and Kumaraswamy, K., (2016). Patterns of Crop Concentration and Diversification in Aiyar basin, Central Tamil Nadu. Punjab Geographer, 12:97-112.

Gupta, P.K., Sharma, D., (2018). Assessment of hydrological and hydrochemical vulnerability of groundwater in semi-arid region of Rajasthan, India. Sustainable Water Resources Management, 5:847-861 https://doi.org/10.1007/s40899-018-0260-6

Kumar, M., Kumari, K., Ramanathan, A. et al., (2007). A comparative evaluation of groundwater suitability for irrigation and drinking purposes in two intensively cultivated districts of Punjab, India. Environmental Geology, 53:553-574. https://doi.org/10.1007/s00254-007-0672-3

Mitchell, A., (2005). The ESRI Guide to GIS Analysis, Volume 2. ESRI Press, Red Lands.

Morris, B.L., Lawrence, A.R.L., Chilton, P.J.C., Adams, B., Calow R.C., Klinck, B.A., (2003). Groundwater and its Susceptibility to Degradation: A Global Assessment of the Problem and Options for Management. Early Warning and Assessment Report Series, RS. 03-3. United Nations Environment Programme, Nairobi.

Nachtergaele, F. Biancalani, R., Petri, M., (2011). Land degradation. SOLAW Background Thematic Report 3. Food and Agricultural Organization, Rome http://www.fao.org/nr/solaw/thematic-reports/en/ (15 November 2019)

Reghunath, R., Sreedhara Murthy, T. R., Raghavan, B. R., (2005). Time Series Analysis to Monitor and Assess Water Resources: A Moving Average Approach. Environmental Monitoring and Assessment, 109:65-72.

Singh, A., (2018). Managing the environmental problems of irrigated agriculture through the appraisal of $\begin{array}{llll}\text { groundwater } & \text { recharge. } & \text { Ecological } & \text { Indicators, }\end{array}$ https://doi.org/10.1016/j.ecolind.2017.11.065

Sivasankar, V., Ramachandramoorthy, T., Chandramohan, A., (2013). Deterioration of coastal groundwater quality in Island and mainland regions of Ramanathapuram District, southern India. Environmental Monitoring and Assessment, 185(1):931-944 https://doi.org/10.1007/s10661-012-2604-2 